\title{
Applications and limitations of constrained high-resolution peak fitting on low resolving power mass spectra from the ToF-ACSM
}

Hilkka Timonen et al.

Correspondence to: Hilkka Timonen (hilkka.timonen@ fmi.fi)

The copyright of individual parts of the supplement might differ from the CC-BY 3.0 licence. 


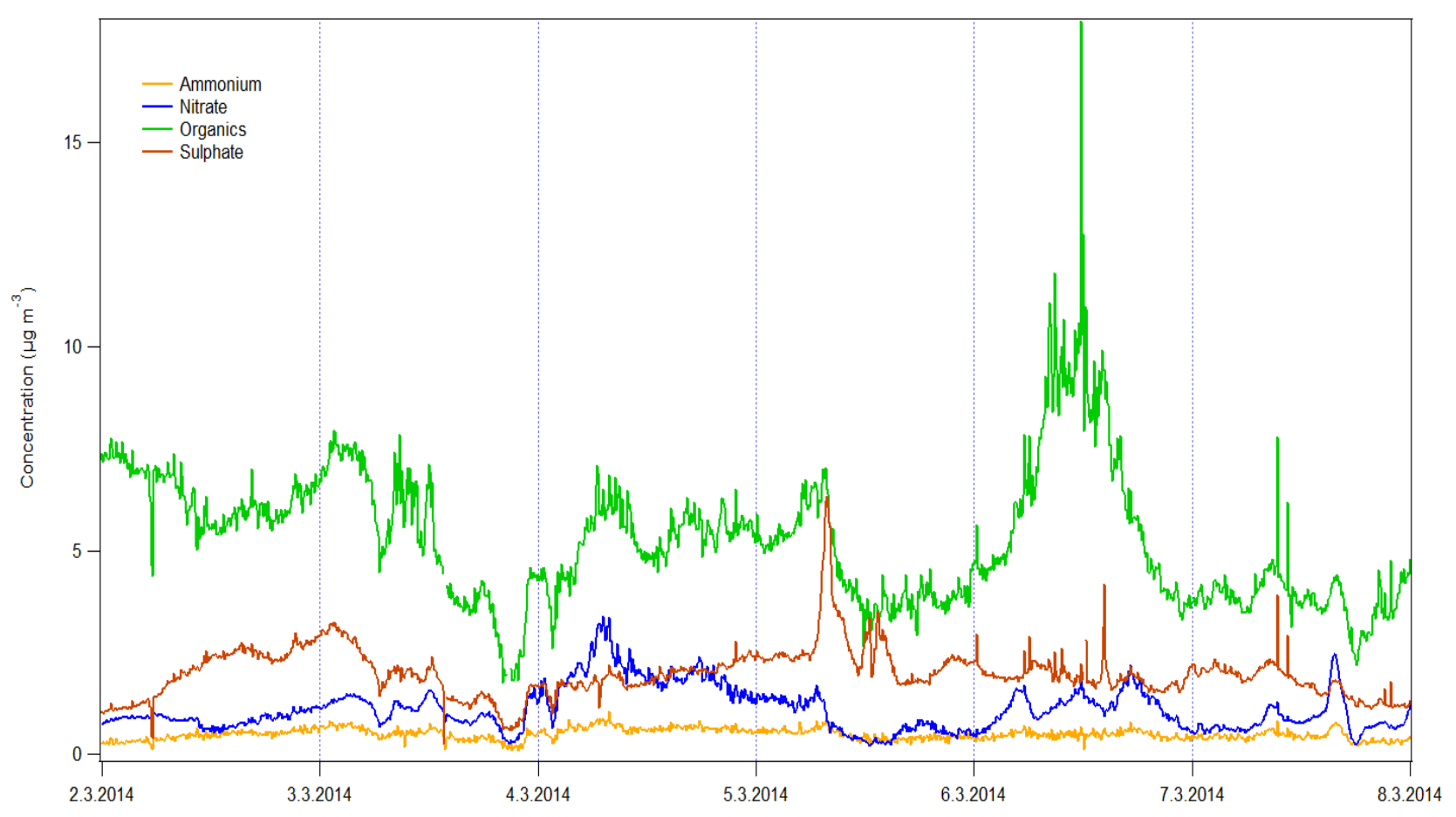

Figure S1: Time series of main ions measured at the SMEARIII station with a ToFACSM during the spring 2014 campaign. 


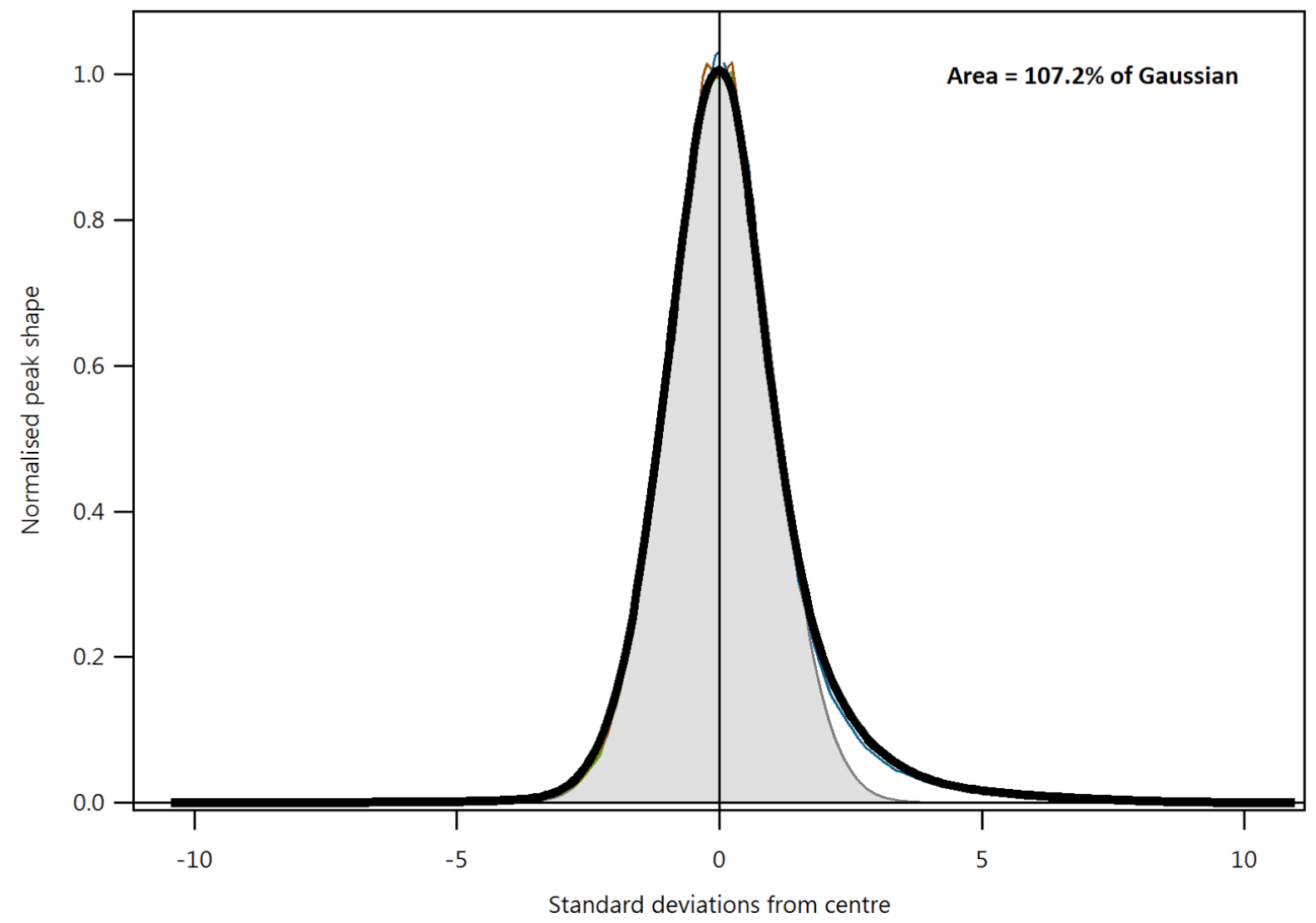

Figure S2: The observed non-Gaussian peak shape calculated using a representative mass spectrum from the SMEARIII campaign data. 


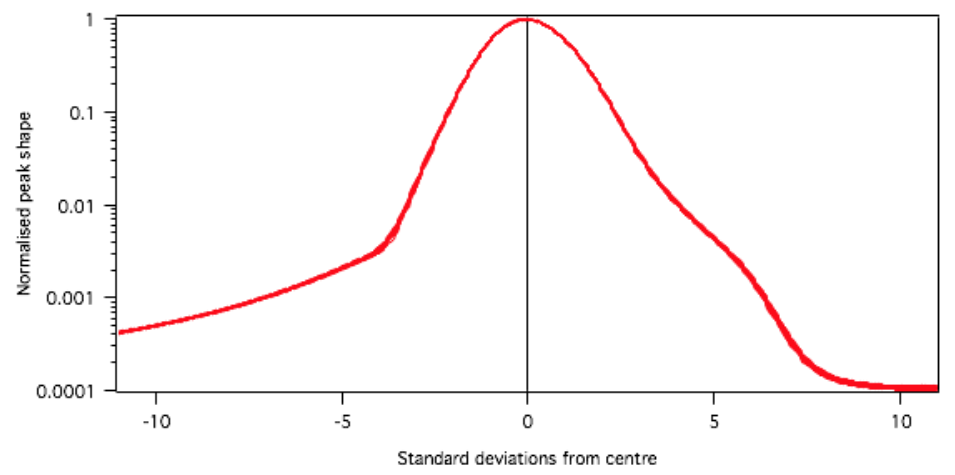

Figure S3: Normalised peak shape for the $\mathrm{N}_{2}{ }^{+}$ion peak at $28 \mathrm{Th}$ from 25 daily averages representing nearly a month of acquired data with consistent TOF tuning (voltages). No significant changes are observed over this time period, such that the individual traces are barely visible.

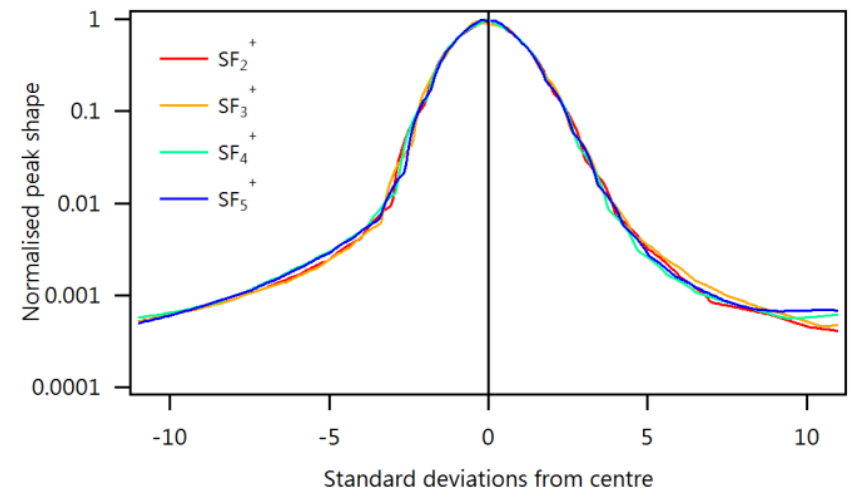

Figure S4: Normalised peak shape for various ions across a calibration $\mathrm{MS}$ with $\mathrm{SF}_{6}$ gas: peak shape is consistent for the different $\mathrm{SF}_{6}$ fragment ions and shows no obvious trend with mass-to-charge ratio. 


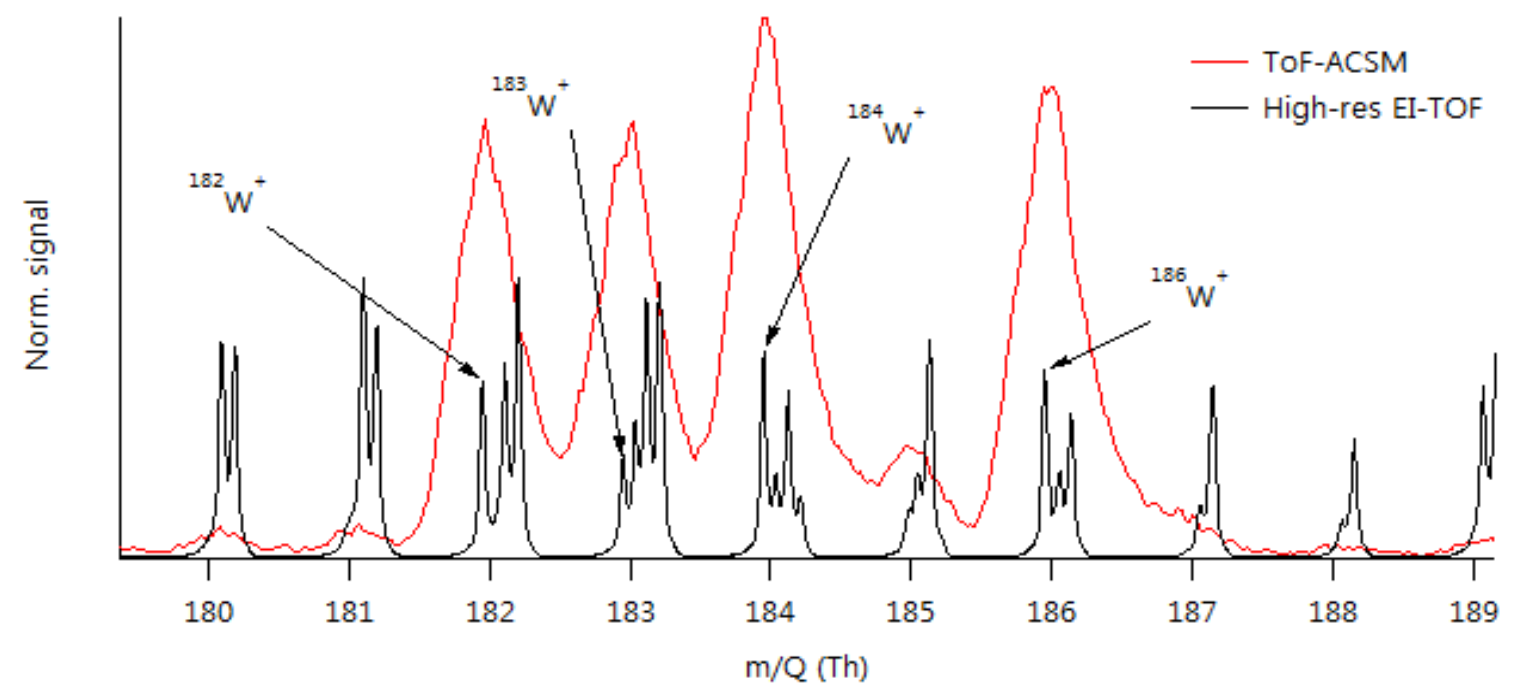

Figure S5: Comparison of a high-resolution EI-TOF MS with that from the ToF-ACSM. Note that the ToF-ACSM tungsten peaks are much stronger relative to the background than is observed in the EITOF. The multiple ions visible in the EI-TOF are measured as only single, broad, peaks in the ToFACSM.

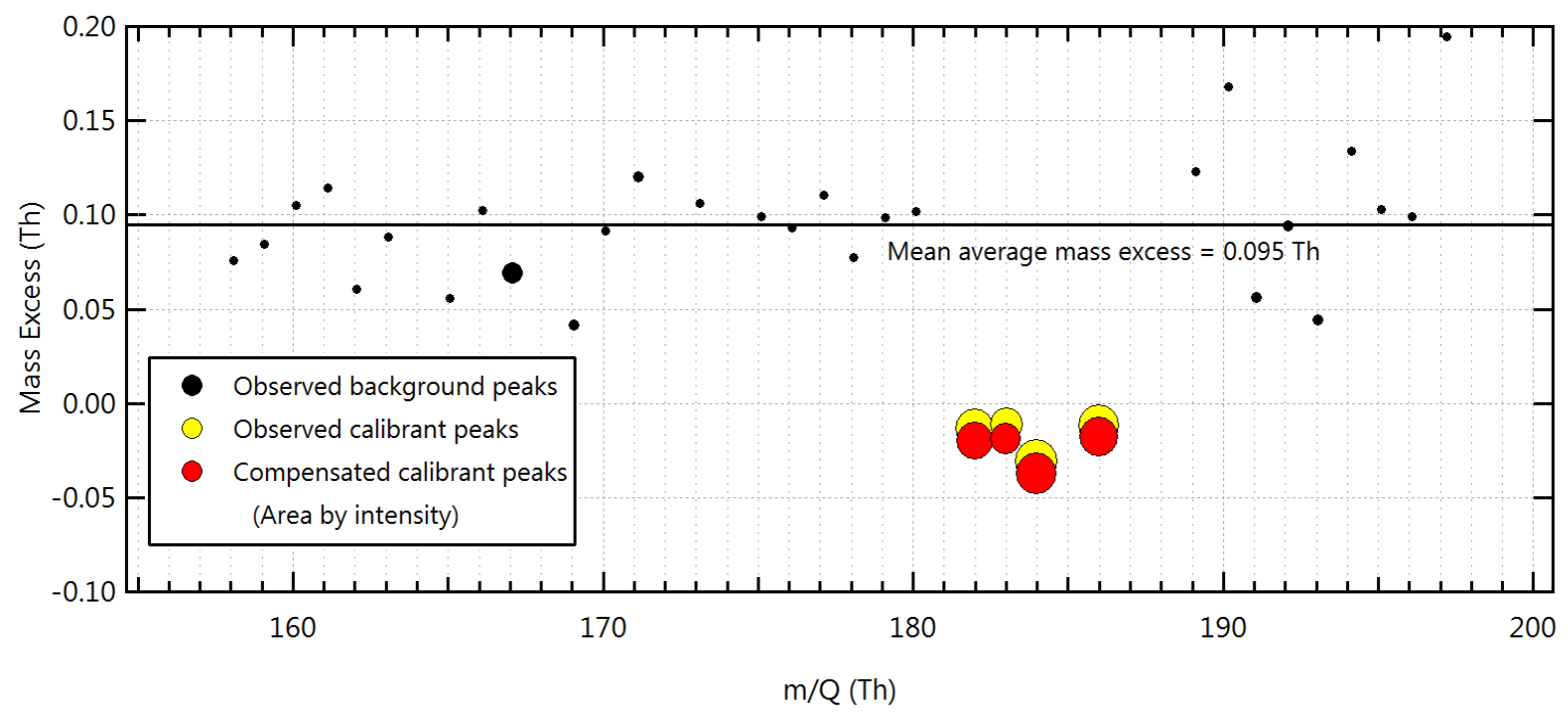

Figure S6: Compensating for the mass positions of calibrant peaks by assuming interferences are present of equal magnitude and mass excess to the surrounding isobaric peaks. 


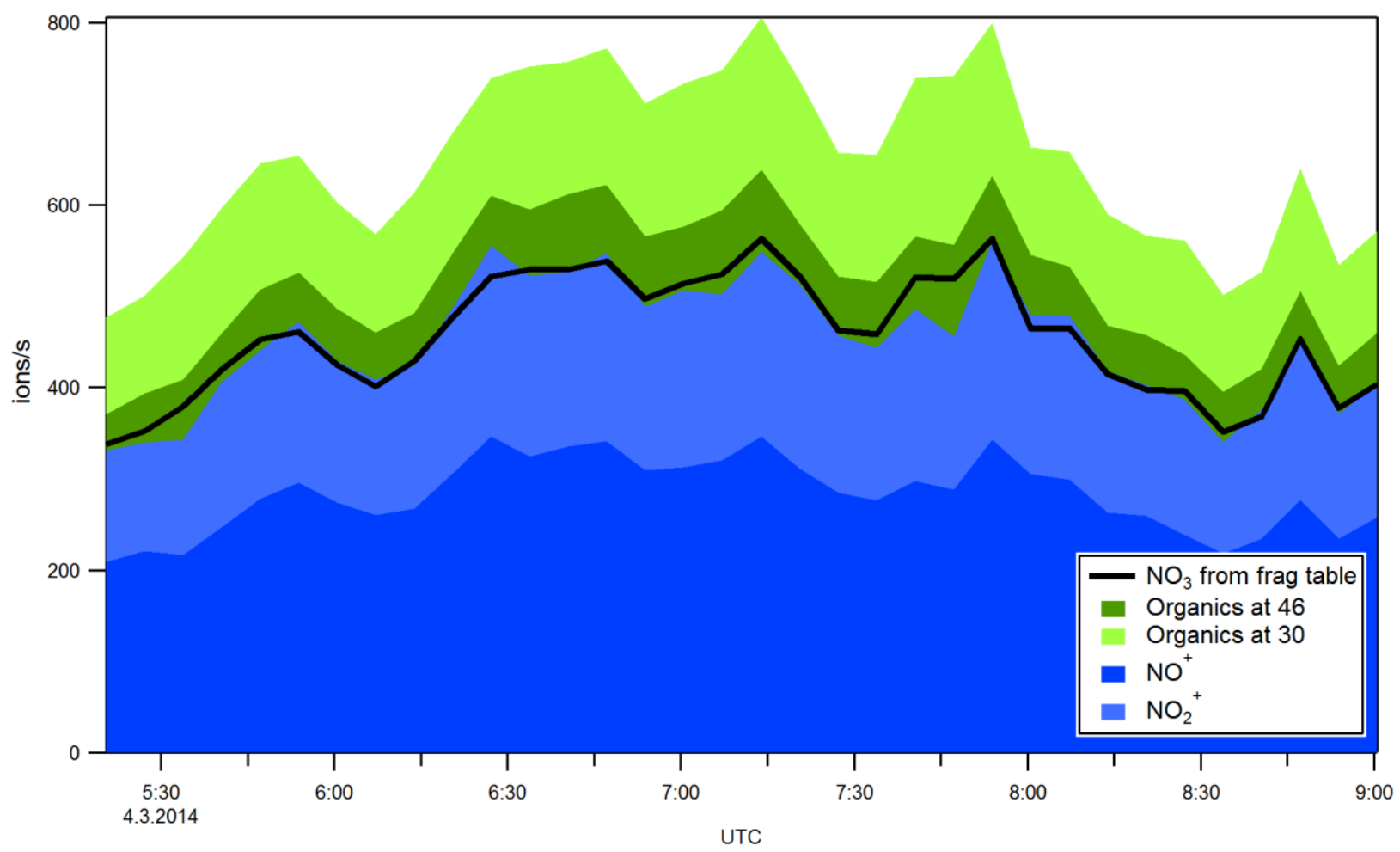

Fig S7: Time-series of the nitrate intensity derived from application of the fragmentation table to integrated (UMR) data compared to the sum of the fitted intensities for the nitrate ions $\mathrm{NO}^{+}$and $\mathrm{NO}_{2}{ }^{+}$and their isobaric organic interferences. On average, the sum of $\mathrm{NO}^{+}$andNO${ }_{2}{ }^{+}$represents $102.7 \%$ of the integrated signal. 

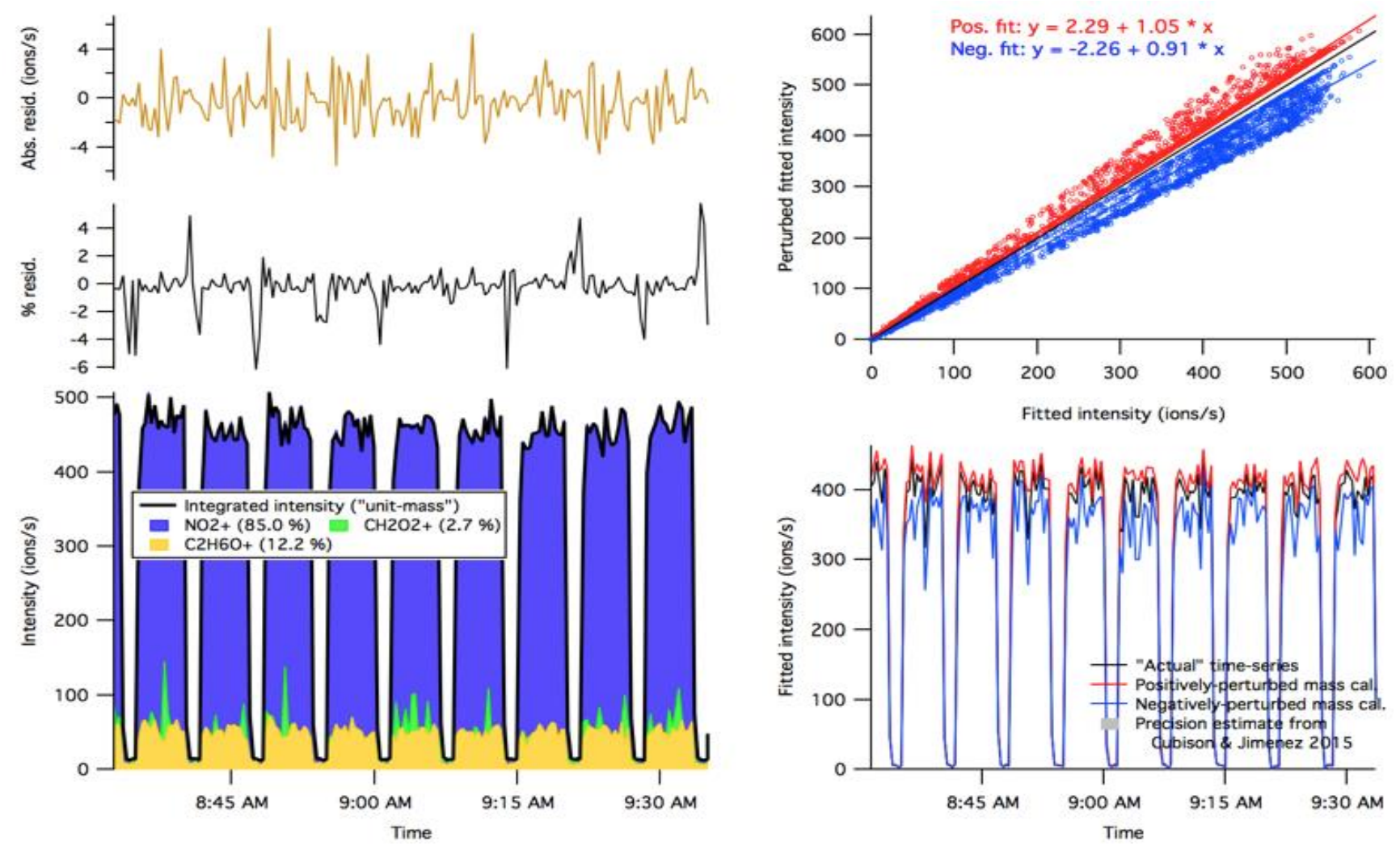

Figure S8: Sensitivity analysis for $\mathrm{NO}_{2}{ }^{+}$using mass calibration perturbations of $+/-20$ ppm. 

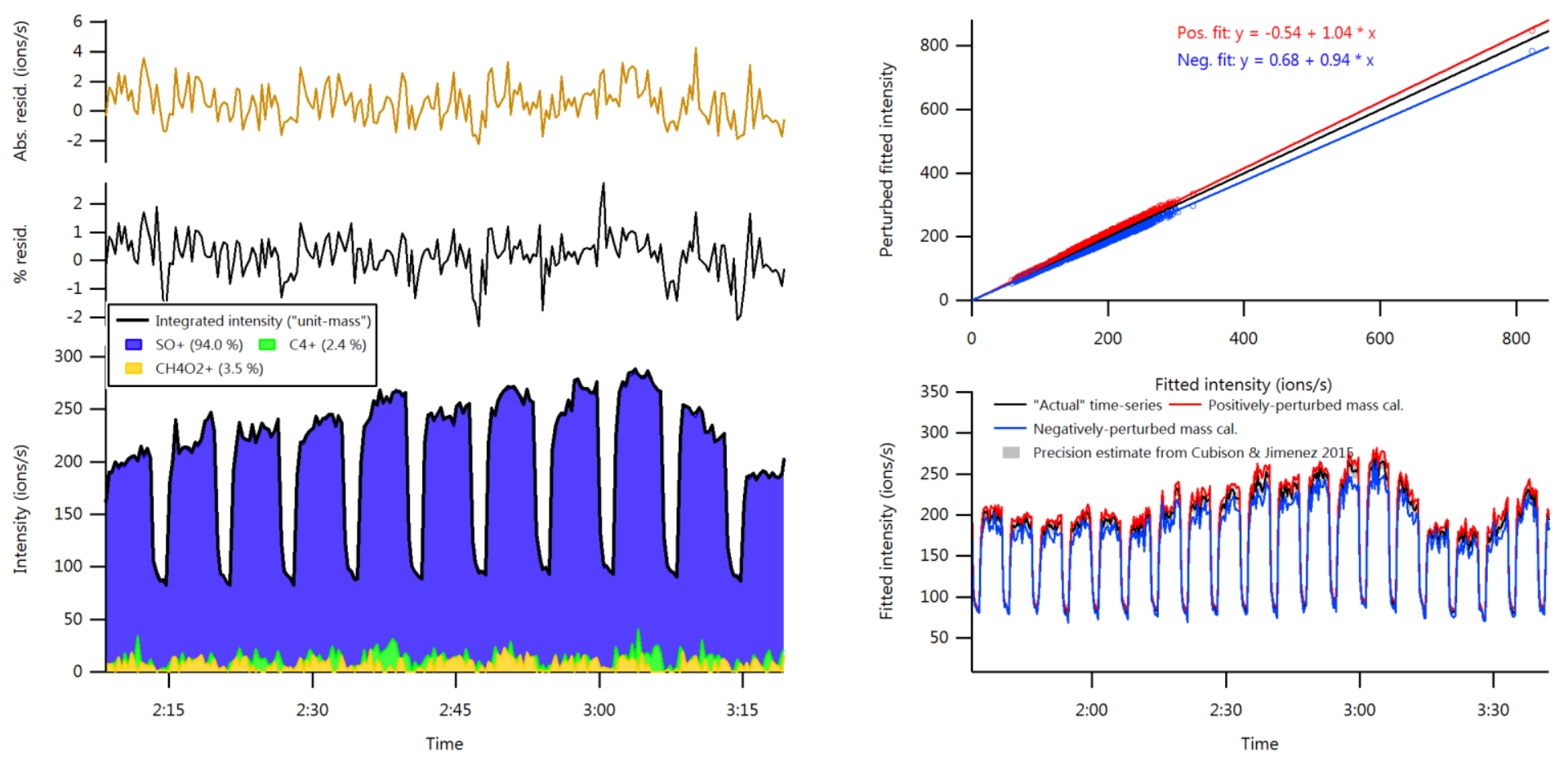

Figure S9: Sensitivity analysis for $\mathrm{SO}^{+}$using mass calibration perturbations of $+/-20 \mathrm{ppm}$. 

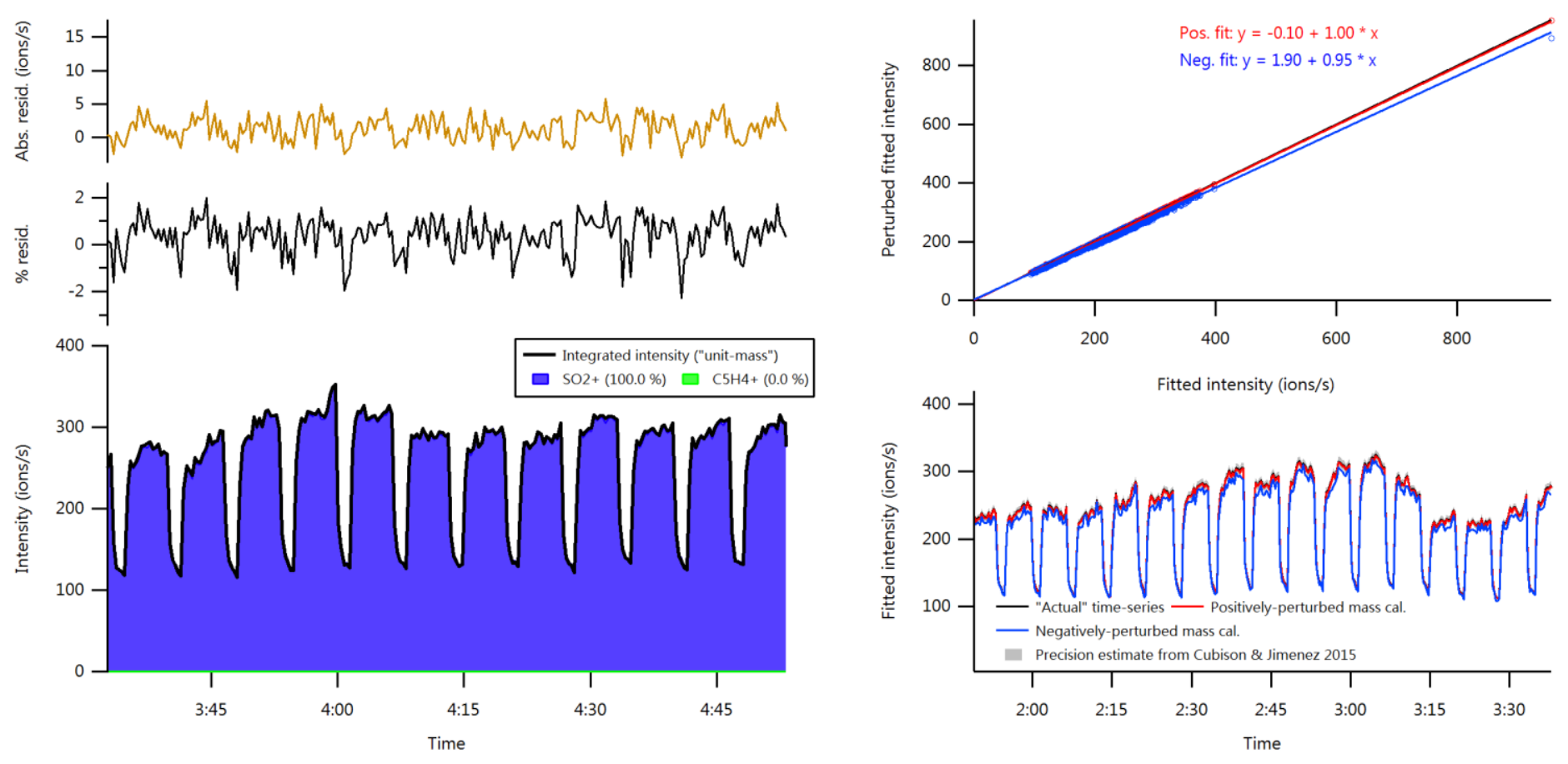

Figure S10: Sensitivity analysis for $\mathrm{SO}_{2}{ }^{+}$using mass calibration perturbations of +/- $50 \mathrm{ppm}$. 

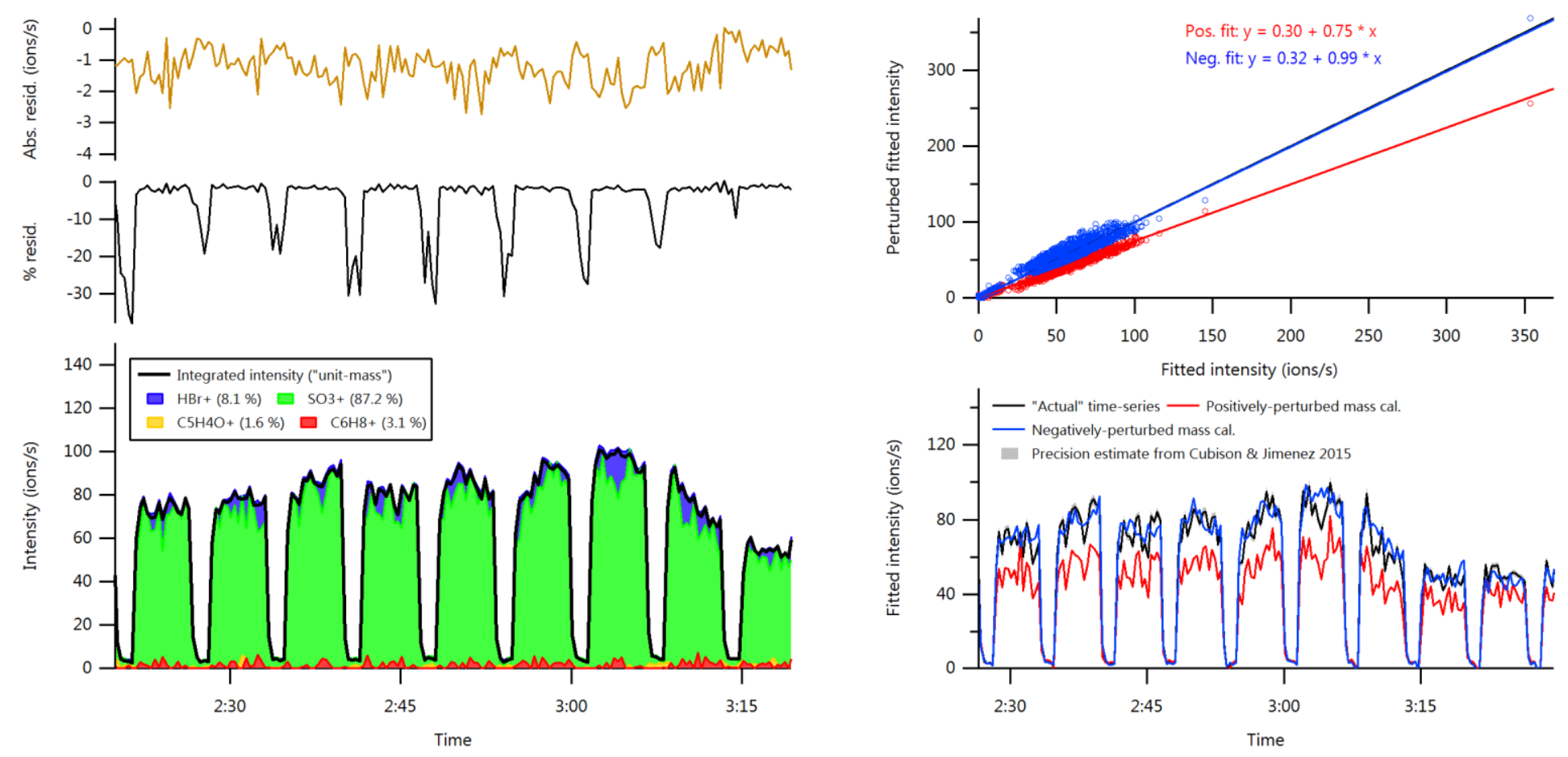

Figure S11: Sensitivity analysis for $\mathrm{SO}_{3}{ }^{+}$using mass calibration perturbations of $+/-50 \mathrm{ppm}$. 

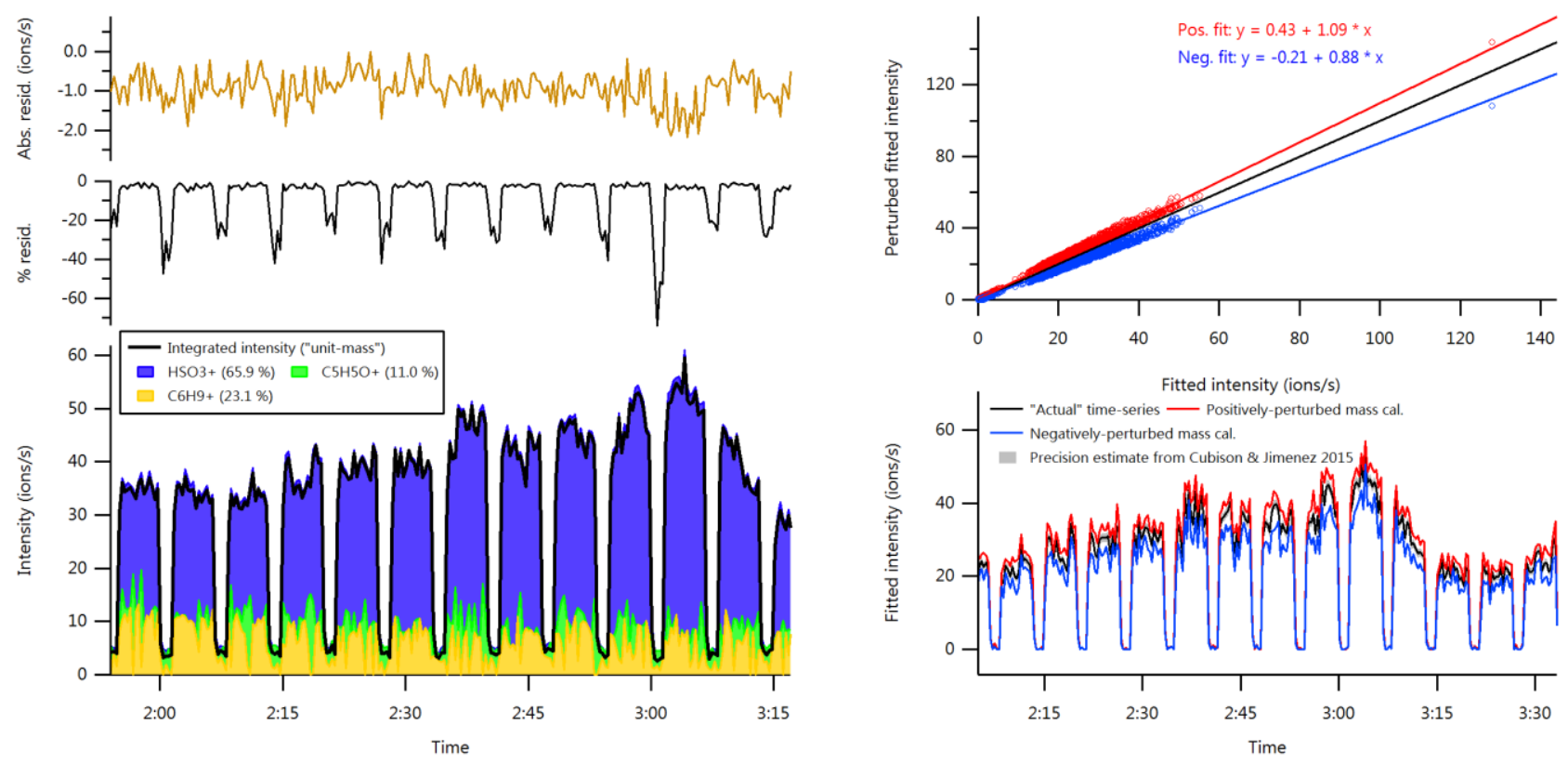

Figure $\mathrm{S} 12$ : Sensitivity analysis for $\mathrm{HSO}_{3}{ }^{+}$using mass calibration perturbations of $+/-50 \mathrm{ppm}$. 

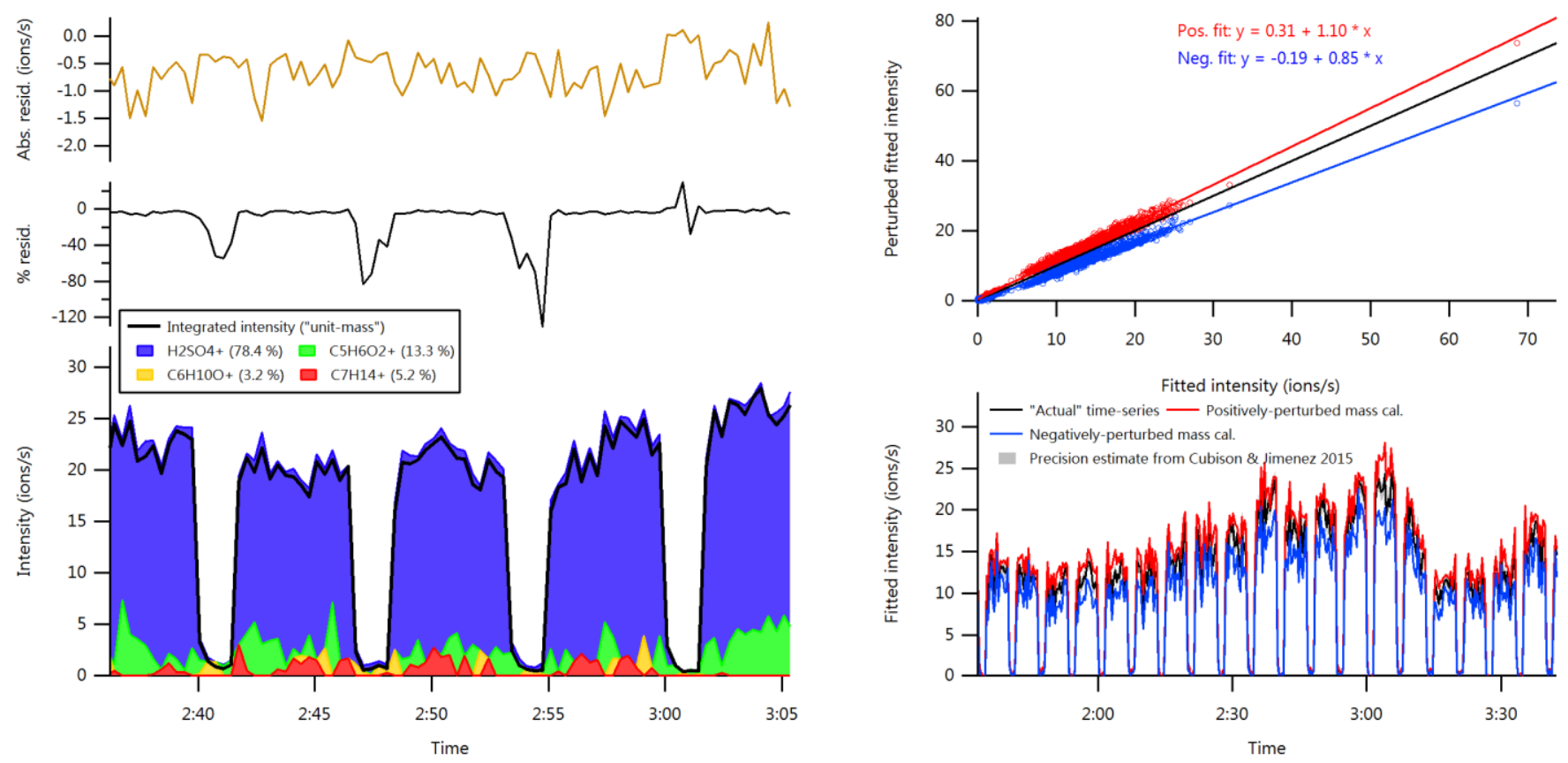

Figure S13: Sensitivity analysis for $\mathrm{H}_{2} \mathrm{SO}_{4}{ }^{+}$using mass calibration perturbations of $+/-50 \mathrm{ppm}$. 


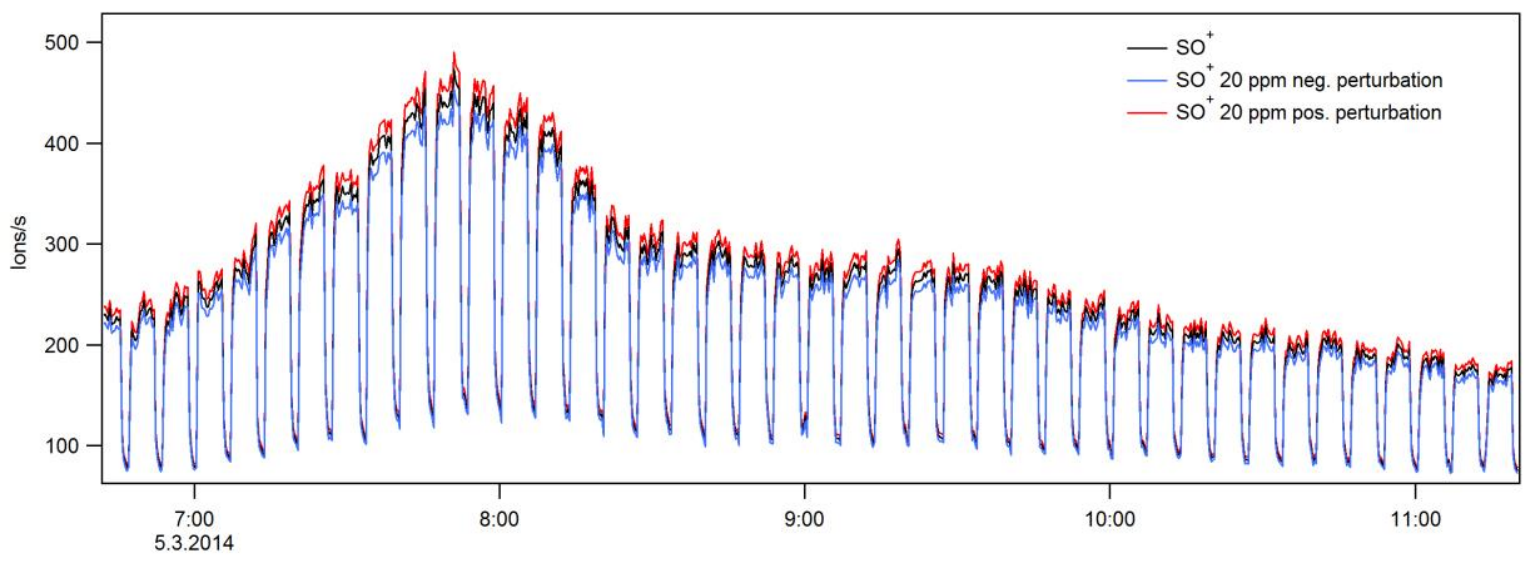

Figure S14: shows an example of positively and negatively perturbed time series for $\mathrm{SO}^{+}$-ion measured during the SMEARIII campaign. The difference between both negatively and positively perturbed and unperturbed time series was on average $4 \%$. 


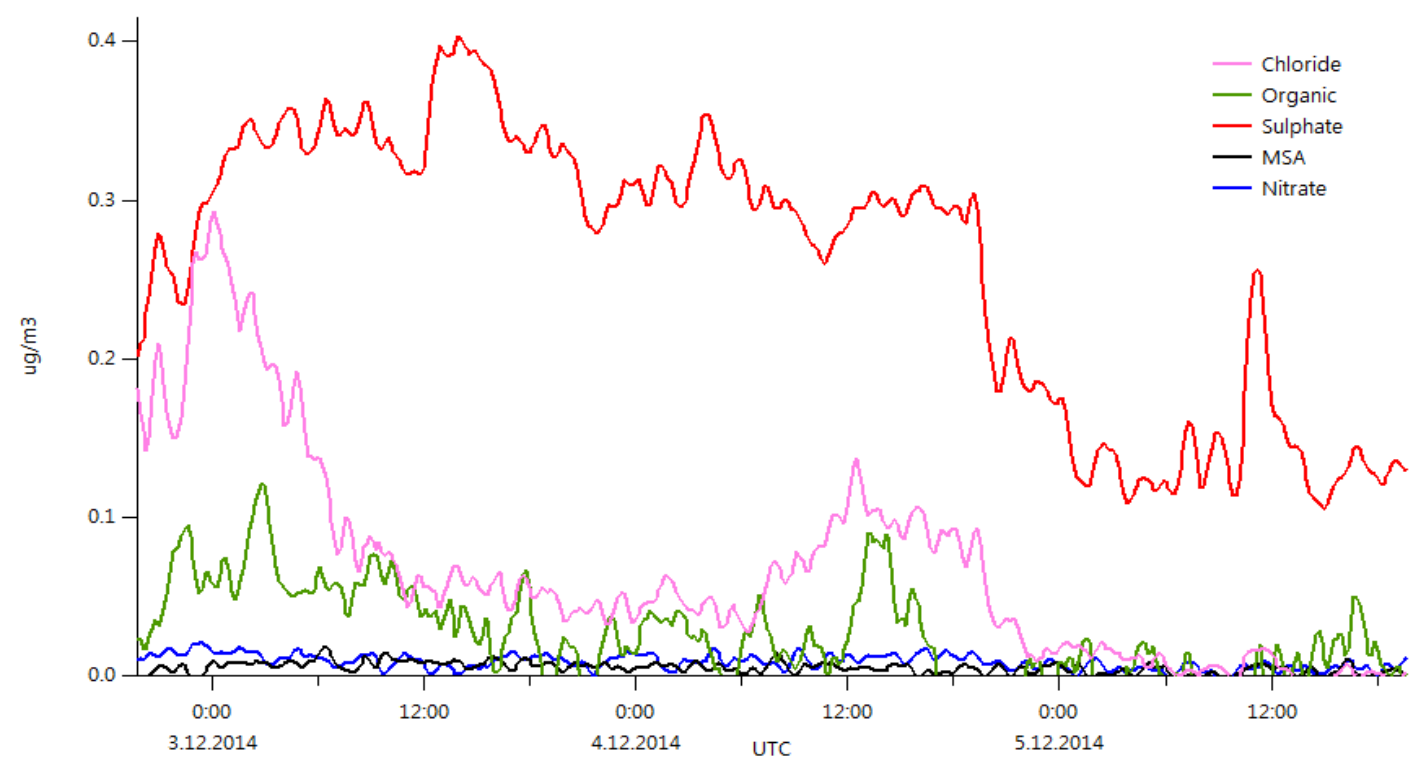

Figure S15: Time-series of ACSM species during episode 1 derived from integrated peak intensities observed with the ToF-ACSM at the Neumayer station at the beginning of December 2014.

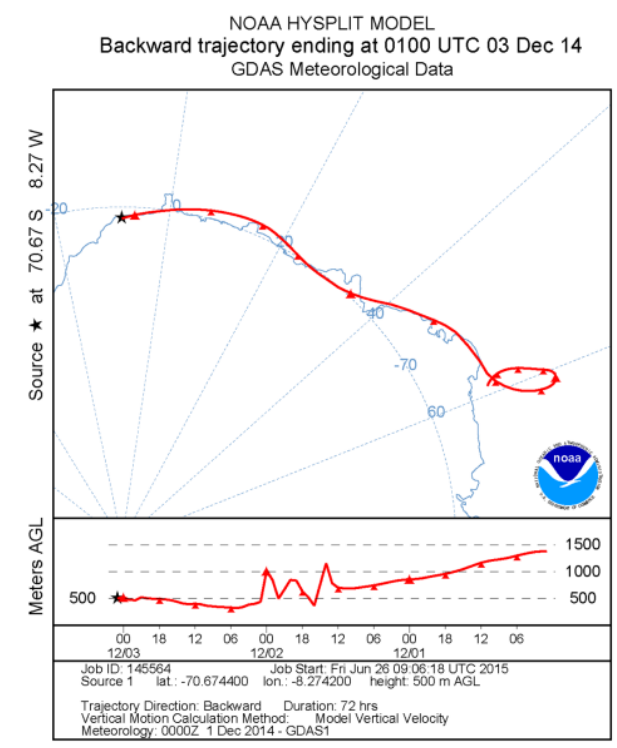

Figure S16: Airmass backtrajectory during episode 1 shows that air mass had transported in low altitude above sea area during last days before arriving to Neumayer station. 


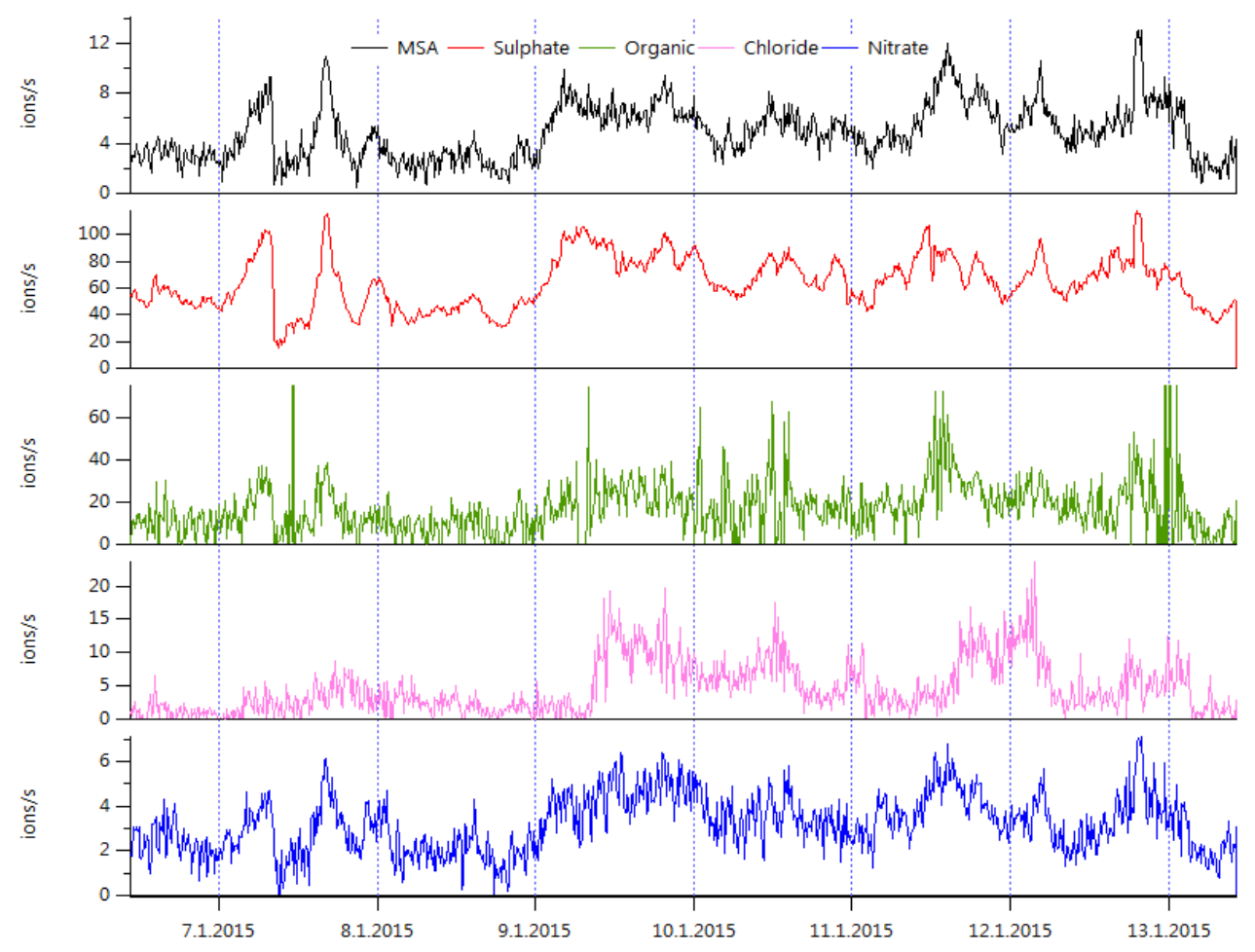

Figure S17: Time-series of ACSM species during episode 2 derived from integrated peak intensities observed with the ToF-ACSM at the Neumayer station in January 2015 . 


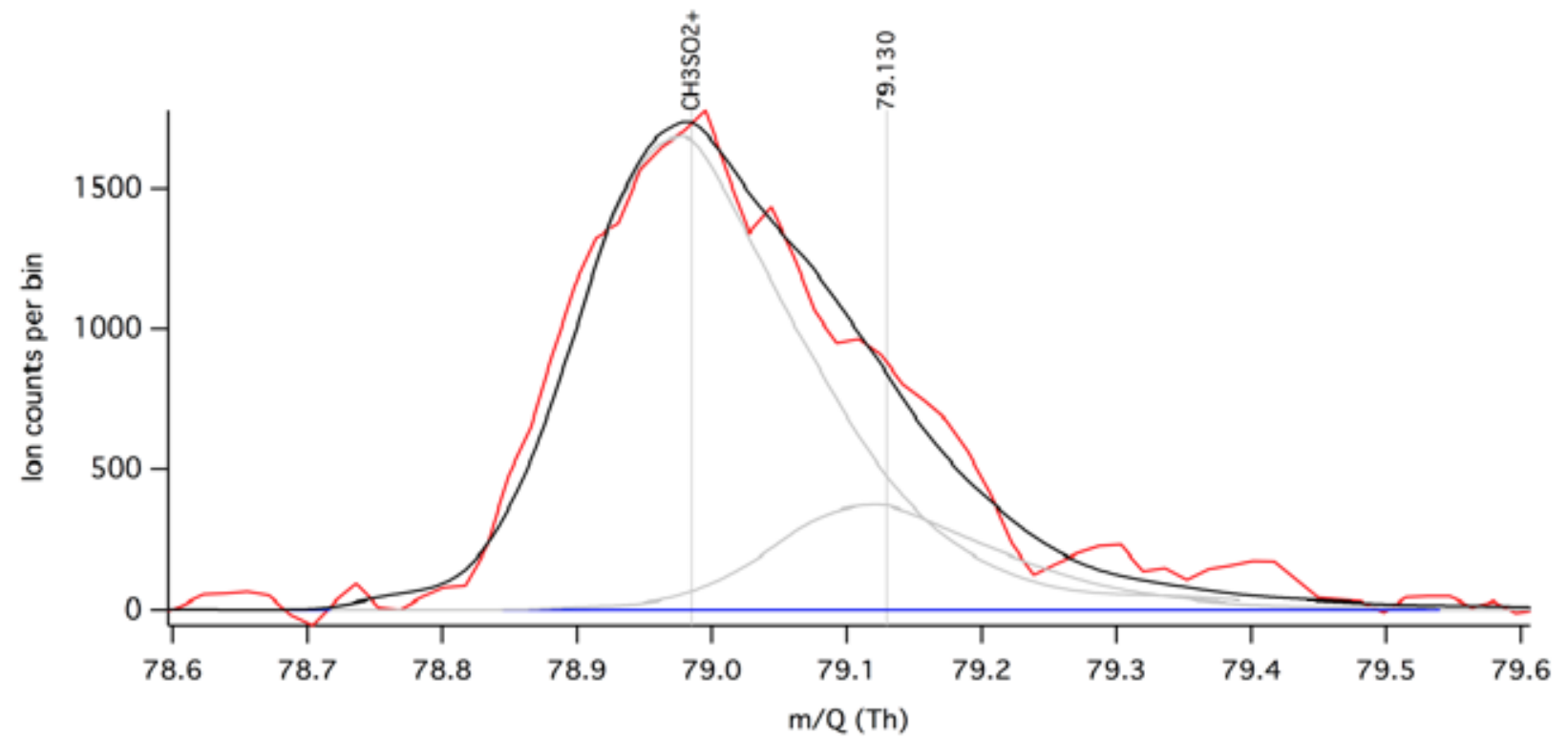

FigureS18: Sensitivity of $\mathrm{CH}_{3} \mathrm{SO}_{2}{ }^{+}$to mass cal @ 100 ppm: 5\% -> clear that this peak is nearly all MSA. 
a)

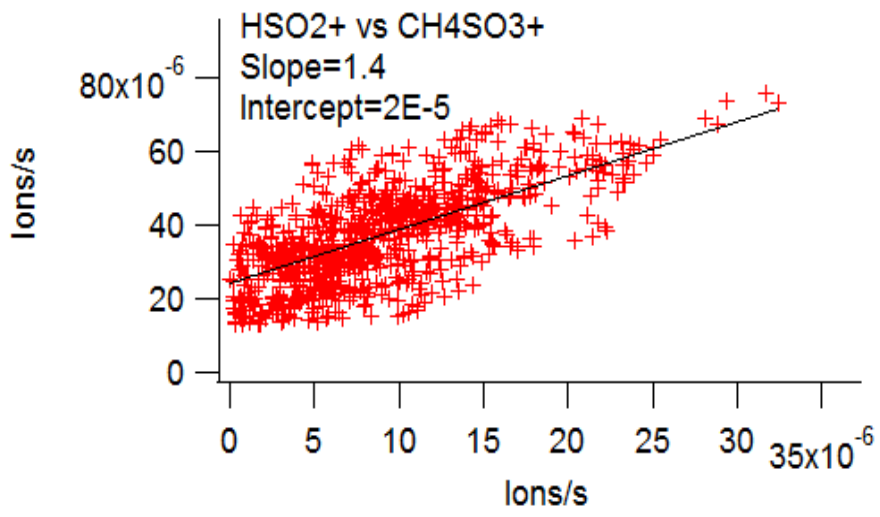

b)

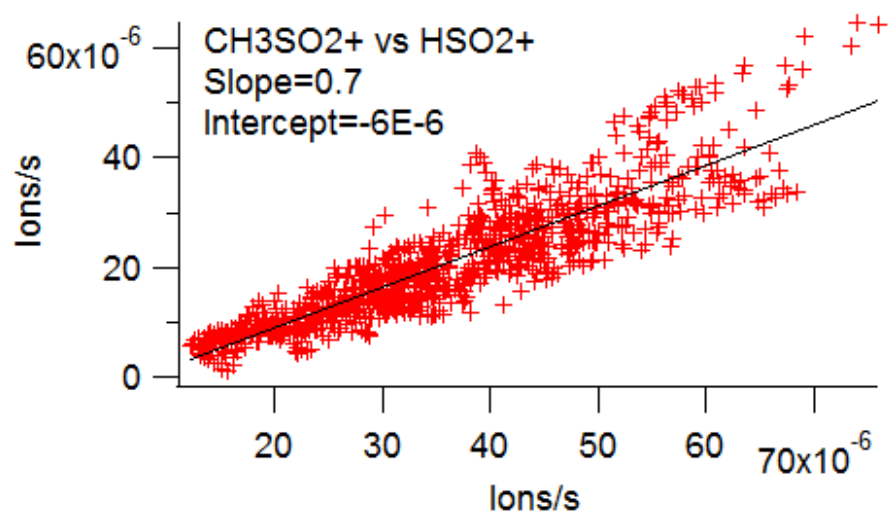

c)

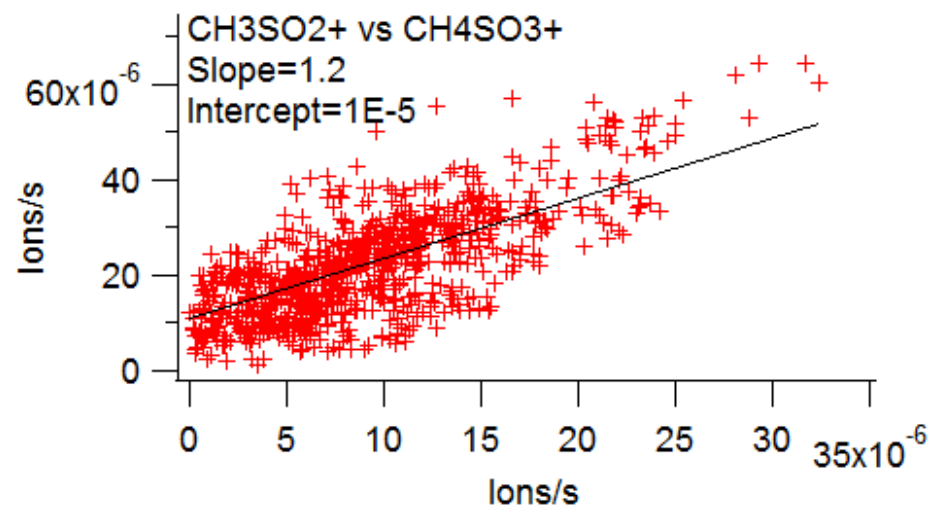

Figure S19: Correlation between MSA main fragments a) $\mathrm{HSO}_{2}{ }^{+} \mathrm{vs} \mathrm{CH}_{4} \mathrm{SO}_{3}{ }^{+}$, b) $\mathrm{CH}_{3} \mathrm{SO}_{2}{ }^{+}$vs $\left.\mathrm{HSO}_{2}^{+}, \mathrm{c}\right) \mathrm{CH}_{3} \mathrm{SO}_{2}{ }^{+}$vs $\mathrm{CH}_{4} \mathrm{SO}_{3}{ }^{+}$. 
Table S1: Correlation (Pearson correlation $r$ ) between all fragments associated with the MSA

\begin{tabular}{|c|c|c|c|c|c|c|}
\hline & CH3S+ & CHS+ & $\mathrm{CH} 2 \mathrm{SO}_{2+}$ & CH3SO2+ & HSO2+ & $\mathrm{CH}_{4} \mathrm{SO}_{3+}$ \\
\hline CH3S+ & 1 & & & & & \\
\hline CHS+ & 0.061827 & 1 & & & & \\
\hline $\mathrm{CH} 2 \mathrm{SO} 2+$ & 0.135439 & 0.294476 & 1 & & & \\
\hline CH3SO2+ & 0.237239 & 0.446346 & 0.696882 & 1 & & \\
\hline HSO2+ & 0.265439 & 0.36614 & 0.598735 & 0.892511 & 1 & \\
\hline CH4SO3+ & 0.232336 & 0.333807 & 0.534572 & 0.742081 & 0.719259 & 1 \\
\hline
\end{tabular}

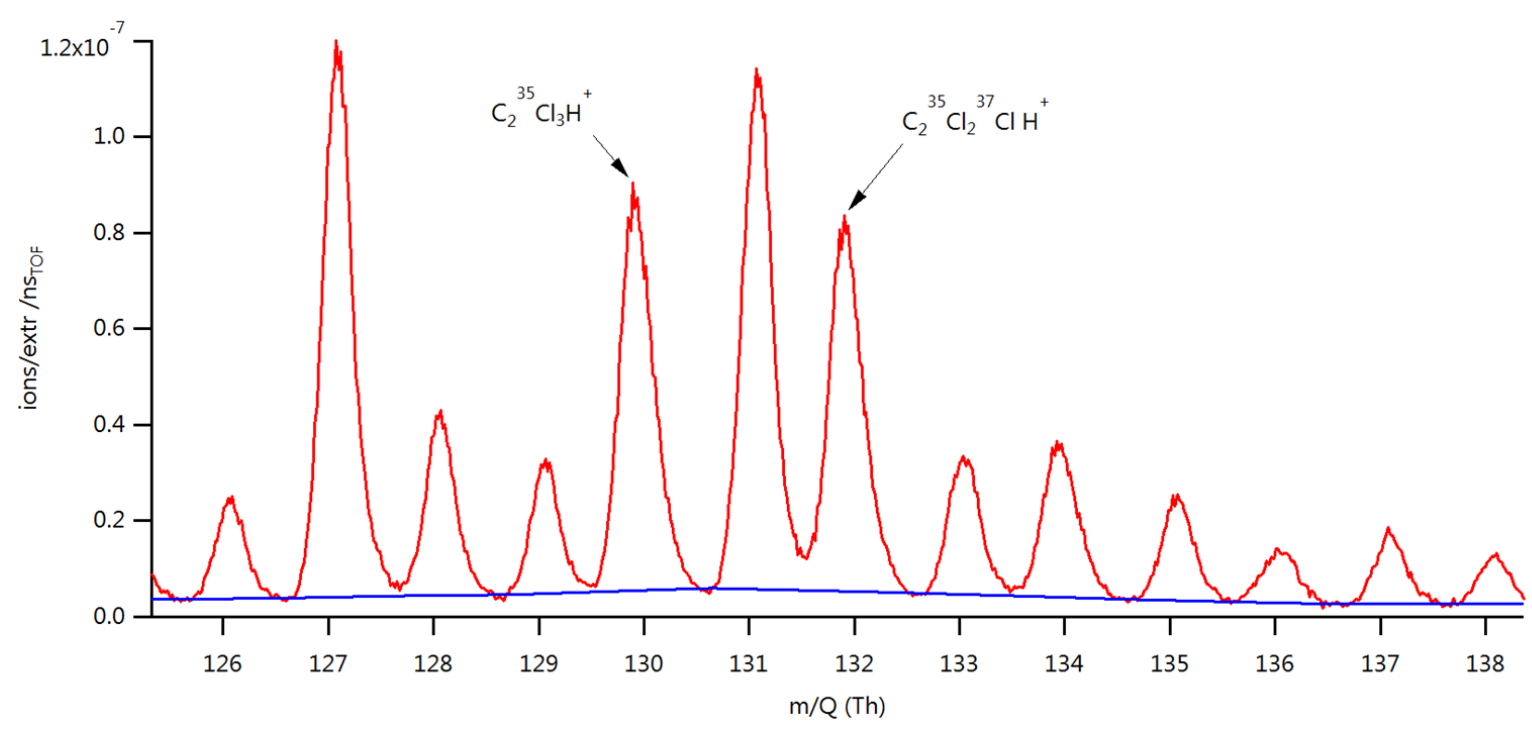

Figure S20: Example MS showing the trichloroethylene peaks with assumed overlapping interferences from organic background ions. The mass defect at 130 and $132 \mathrm{Th}$ is visibly more negative than at the surrounding peaks. 


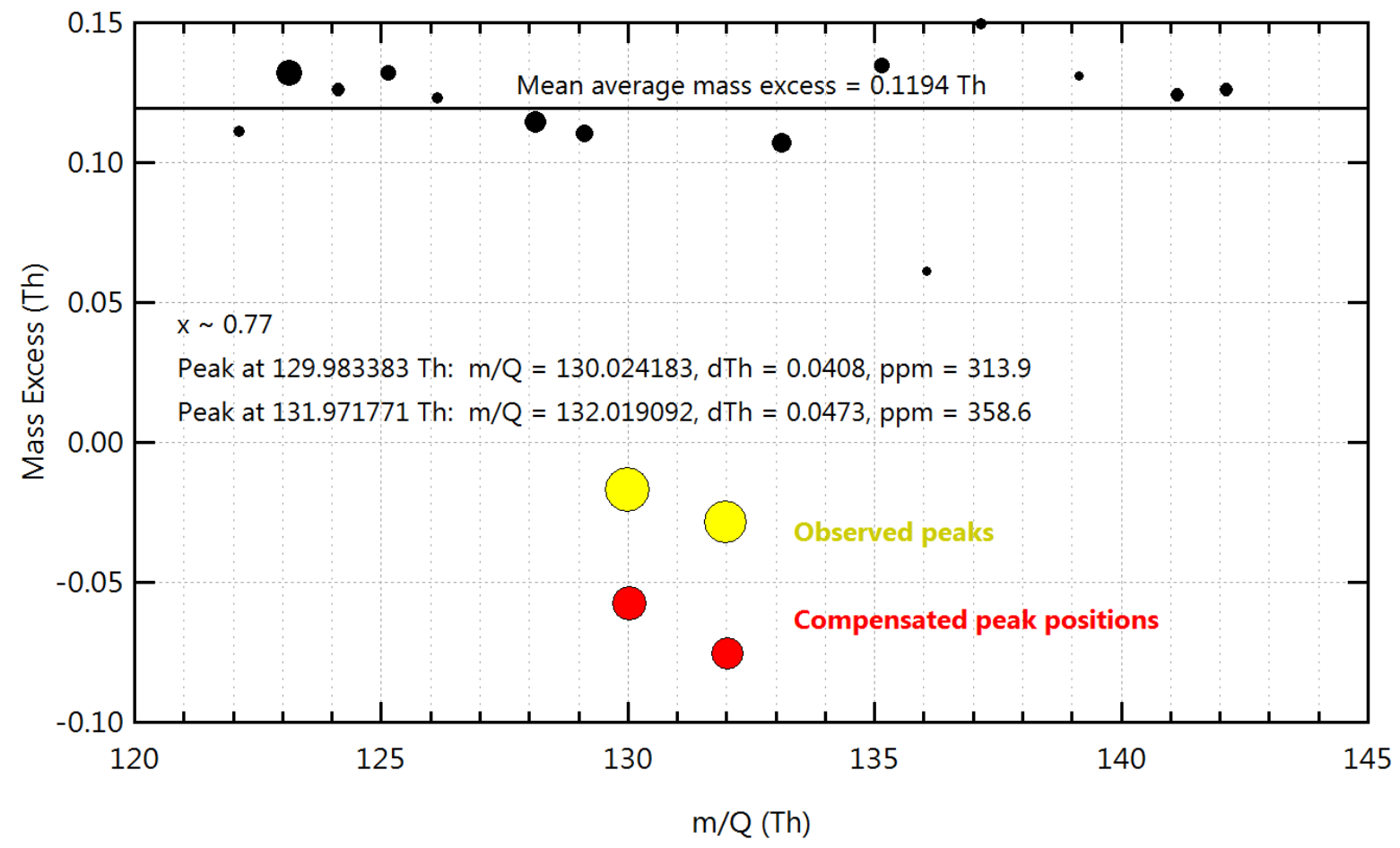

Fig S21: Compensating for the mass positions of calibrant peaks by assuming interferences are present of equal magnitude and mass defect to the surrounding isobaric peaks.

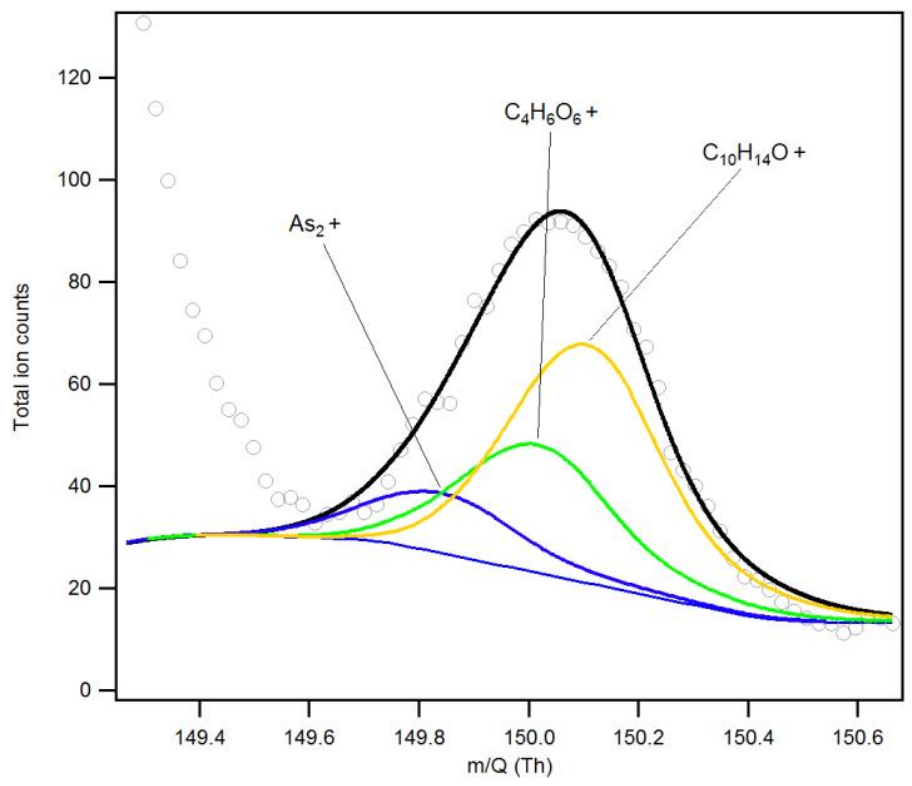

Figure S22: Example mass spectrum showing the HR fits for $\mathrm{As}_{2}{ }^{+}$and the organic background peaks at $150 \mathrm{Th}$. 


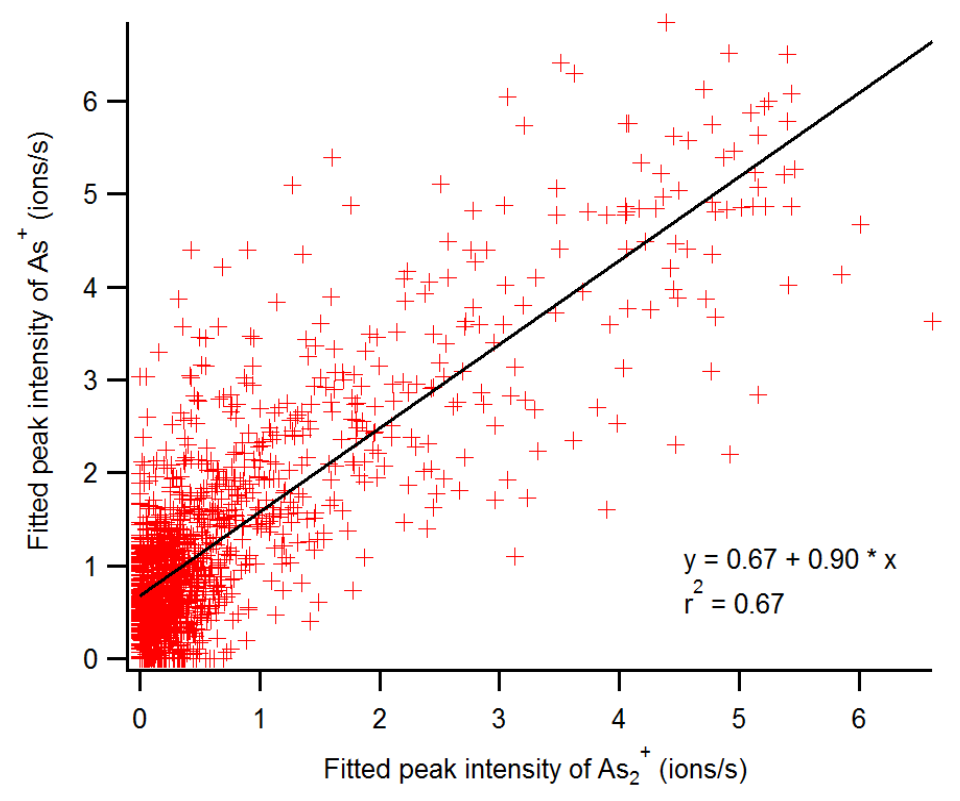

Figure S23: Scatter plot of the fitted peak intensities for $\mathrm{As}^{+}$and $\mathrm{As}_{2}{ }^{+}$.
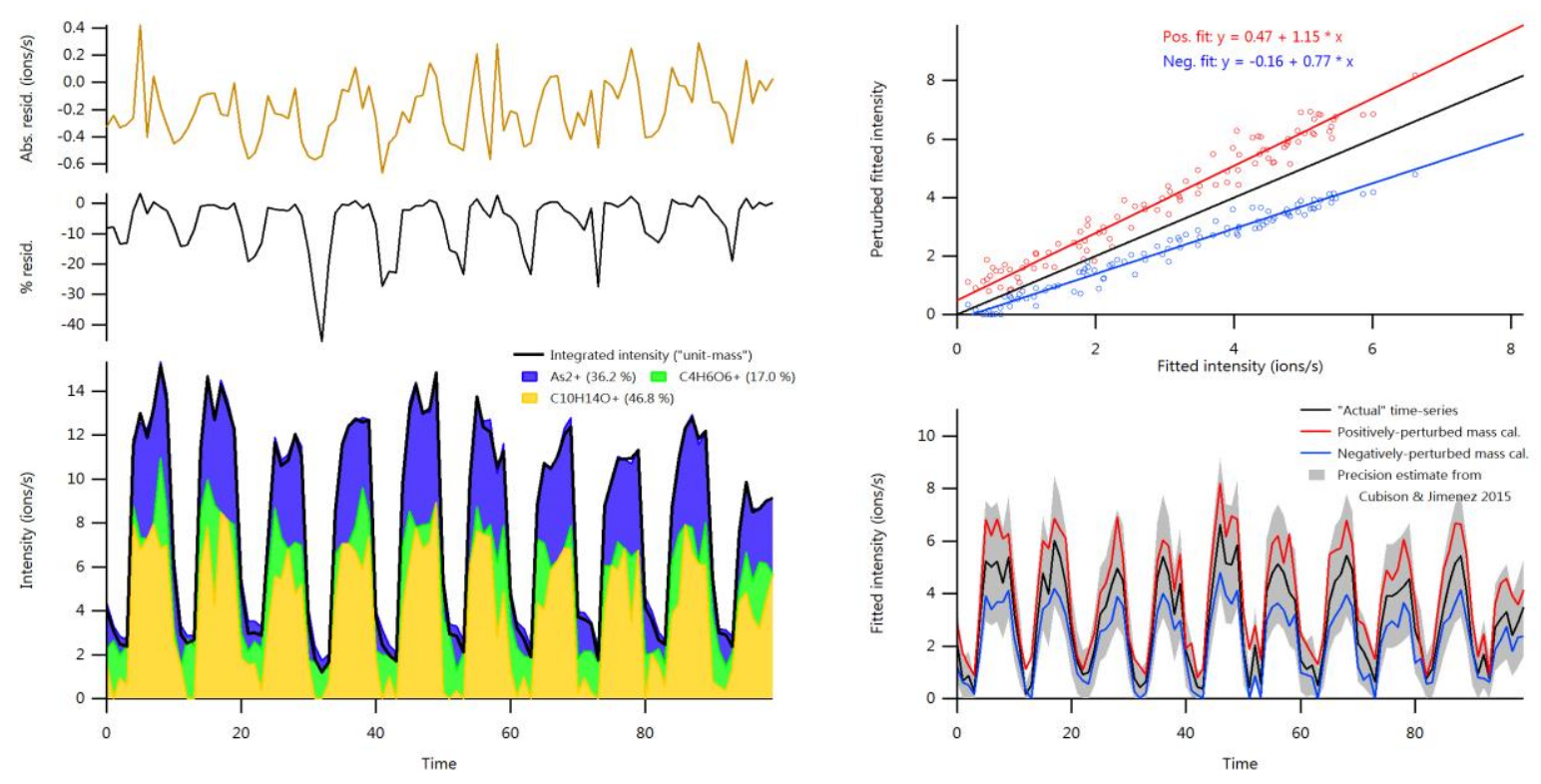

Figure S24: Assessing the sensitivity of the fitted peak intensity of the $\mathrm{As}_{2}{ }^{+}$ion to perturbations in the mass calibration of $+/-200 \mathrm{ppm}$. Left: the sum of the ions fitted at this peak compared with the integrated signal (bottom) and the absolute and relative residuals (top). Top right: Scatter plots of the fitted $\mathrm{As}_{2}{ }^{+}$signals for the perturbed vs best-case mass calibration scenarios. Bottom right: Time-series of the fitted $\mathrm{As}_{2}{ }^{+}$intensities, with the perturbed mass calibration cases shown in red and blue. The shading around the black line indicates the expected precision predicted by the parameterisation of Cubison and Jimenez (2015). 

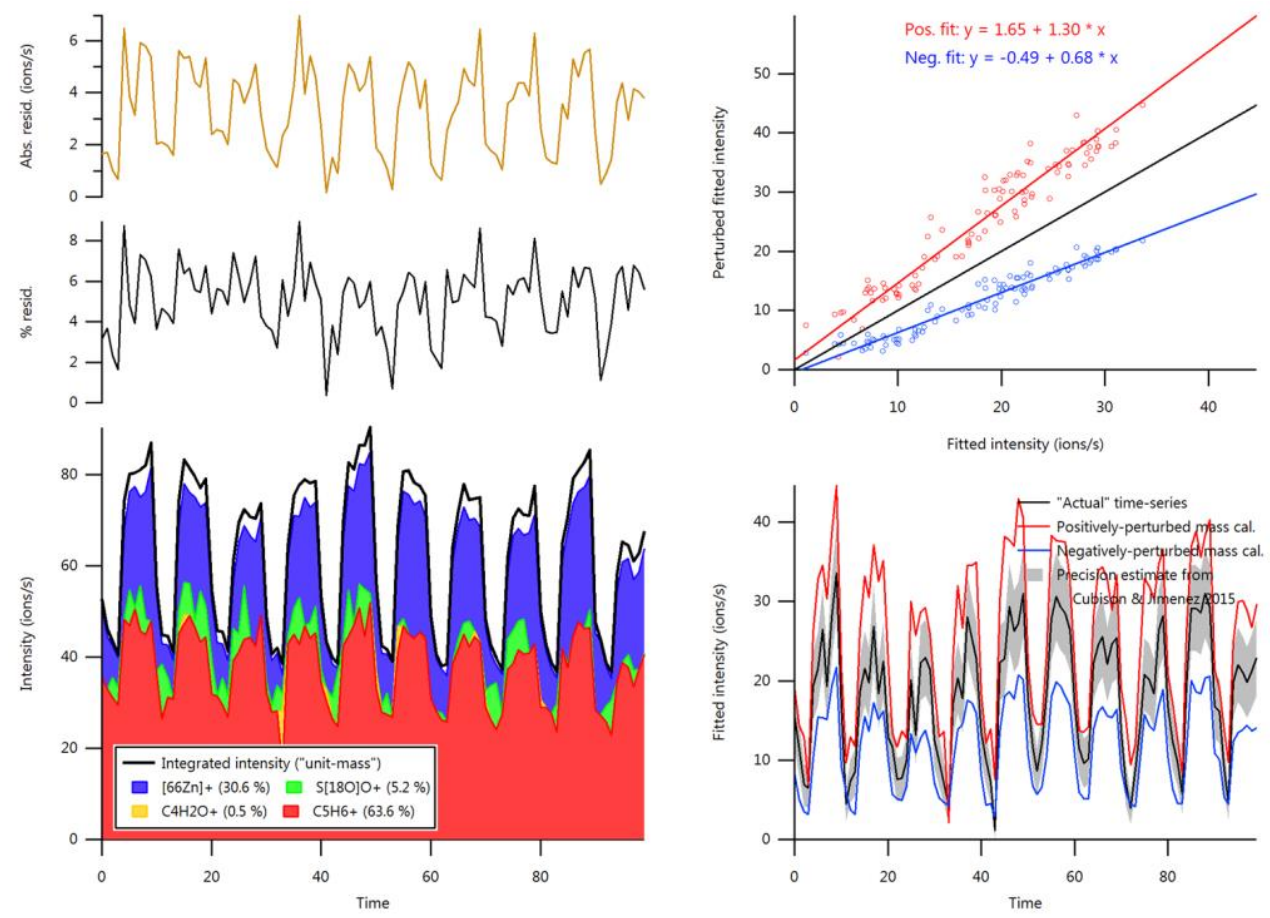

Figure S25: Sensitivity analysis of peak-fitting at 66 Th showing a non-zero contribution from the ion ${ }^{66} \mathrm{Zn}^{+}$. 

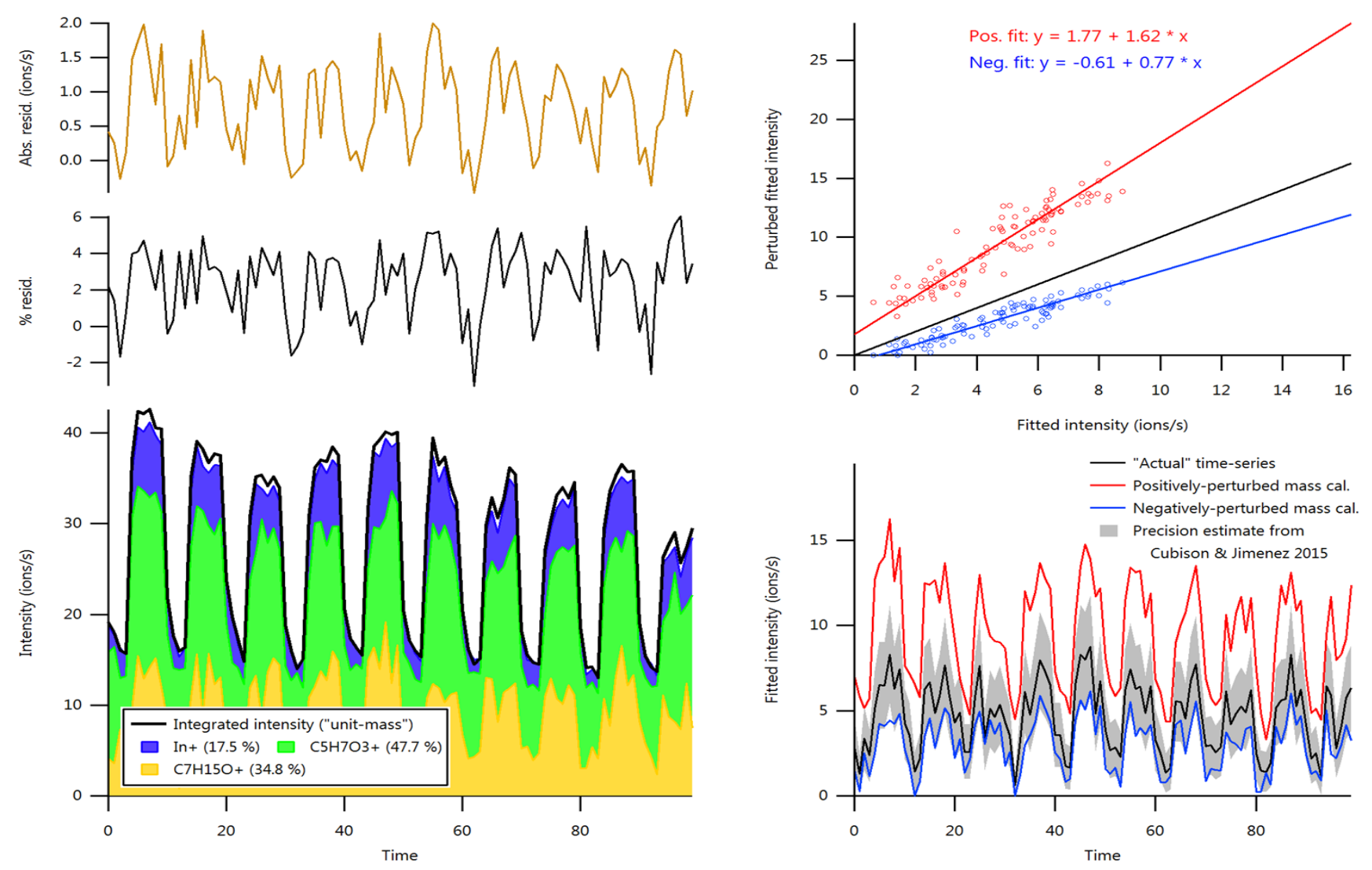

Figure S26: Sensitivity analysis of peak-fitting at 115 Th showing a weak but non-zero contribution from the ion $\mathrm{In}^{+}$. 

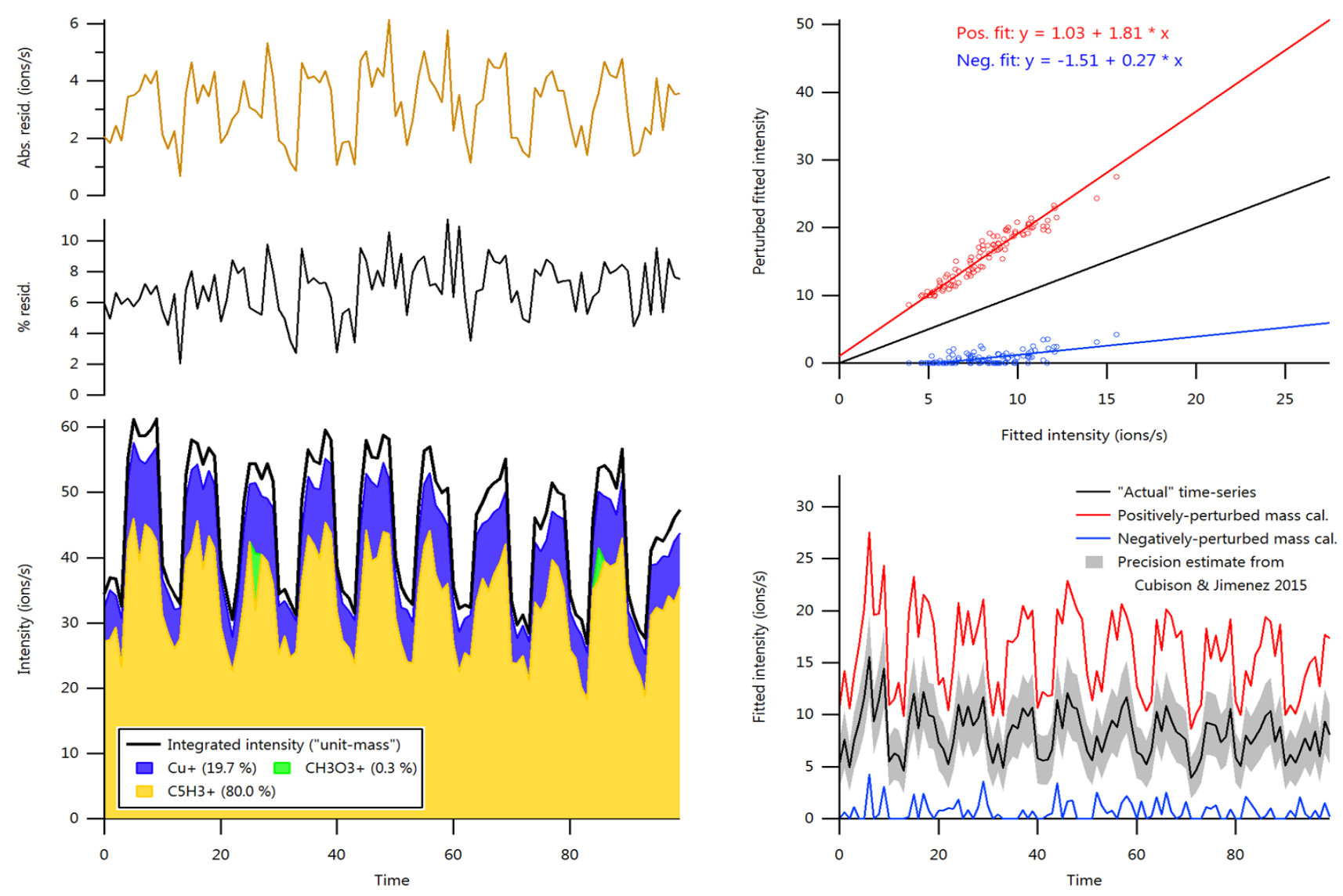

Figure S27: Sensitivity analysis of peak-fitting at 63 Th showing high sensitivity of the fitted intensity of the $\mathrm{Cu}^{+}$ion to mass calibration. 


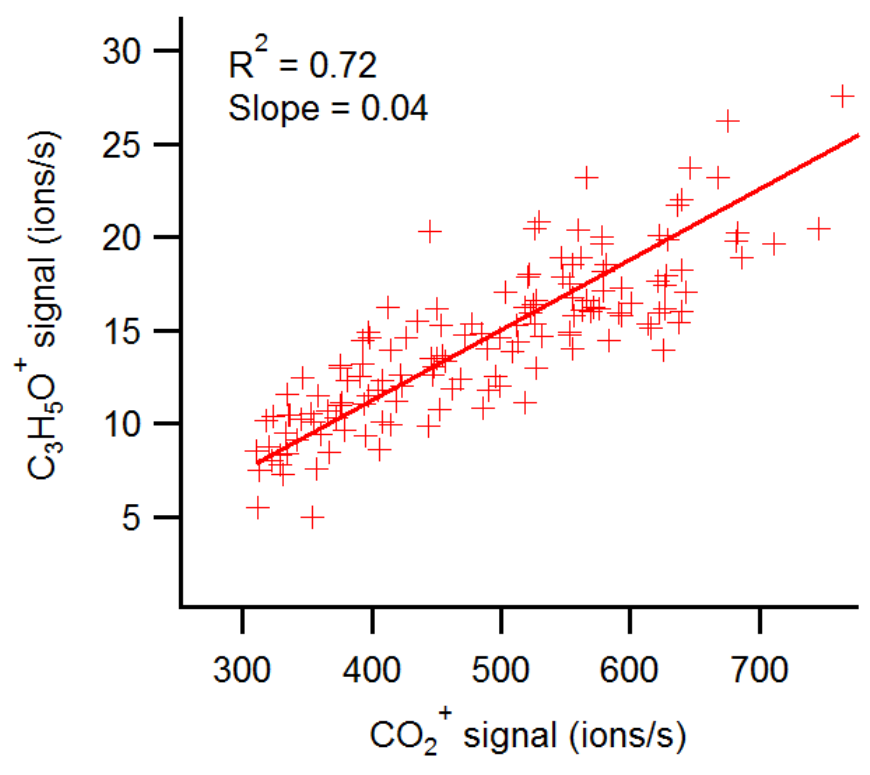

Figure S28: Scatter plot of the difference signal for the fitted intensities of the $\mathrm{C}_{3} \mathrm{H}_{5} \mathrm{O}^{+}$and $\mathrm{CO}_{2}{ }^{+}$ions.

Parameterisation of Stark et al. (2015) for the calculation of carbon oxidation state from mass excess (ME):

$\mathrm{OSc}=\mathrm{A}^{*} \mathrm{ME}+\mathrm{B}^{*} \mathrm{~m} / \mathrm{Q}+\mathrm{C}^{*}[\mathrm{ME} /(\mathrm{m} / \mathrm{Q})]+\mathrm{D}$

where $\mathrm{A}=2.796, \mathrm{~B}=-1.304 \mathrm{e}-3, \mathrm{C}=-4.05 \mathrm{e} 3, \mathrm{D}=1.295$ 